
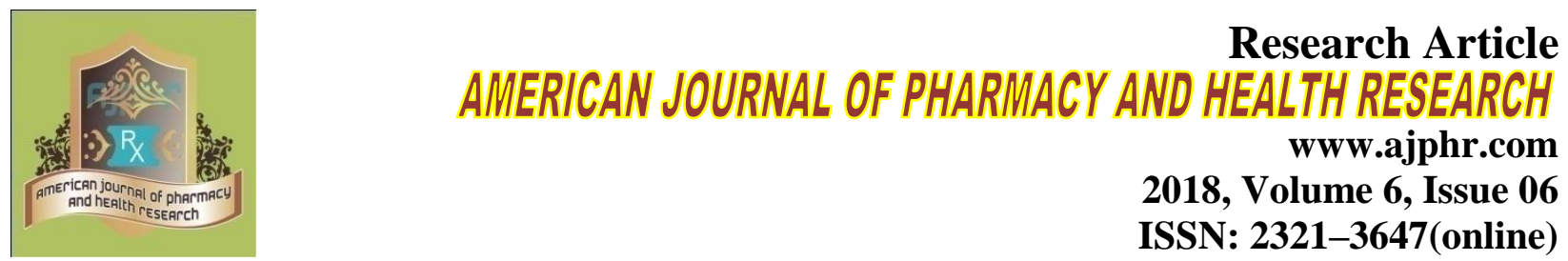

2018, Volume 6, Issue 06

ISSN: 2321-3647(online)

\title{
Raoultella Ornithinolytica Urinary Tract Infections are on the Rise: A Case Report
}

Atif A. Katib ${ }^{1}$, Bassem A. Dakkak ${ }^{1}$, Husam A. Katib², Sara K. Alem²

1. Department of Urology, King Abdul-Aziz hospital, Makkah, Saudi Arabia

2.Faculty of medicine, Ummal-Qura University, Makkah, Saudi Arabia

\section{ABSTRACT}

Community-acquire urinary tract infection (UTI) with Raoultella ornithinolytica is rare, with only 36 cases have been reported in the literature. The case in hand reports a 29 yrs. old lady with pelvic inflammatory disease who suffered from bothering irritative lower urinary tract symptoms (LUTS) ten days after removing an intrauterine contraceptive device. Urine culture recovered the rare bacterium of Raoultella ornithinolytica. Based on the sensitivity result, the patient has been treated with levofloxacin antibiotic and has responded favorably.

Keywords: Raoultella Ornithinolytica, Klebsiella, community-acquire UTI 


\section{INTRODUCTION}

Raoultella ornithinolytica (formerly Klebsiella ornithinolytica) belongs to the genus Raoultella and the family Enterobacteriaceae. It is an oxidase-negative, non-motile, capsulated, facultative aerobic Gram-negative bacillus. Raoultella is named after the French bacteriologist Didier Raoult [1].

To our knowledge, in 2014, Nakasone et al, reported the $11^{\text {th }}$ case of R. ornithinolytica related UTI [2]. Later, in 2016, P. Seng et al presented a literature review documenting 36 UTI cases, 25 of which were clinically cystitis [3]. Therefore, we are reporting the sequential 26th case of R. ornithinolytica related uncomplicated cystitis. Despite human infection with R. ornithinolytica is rare, it has manifested as an infrequent, but important cause of soft tissue infections; e.g. pneumonia, pleural effusion, skin infection, cellulitis, and cholangitis [3]. Some of the infections were serious enough to be life-threatening.

The objective of this treatise was to report a case of community-acquire cystitis caused by the rare pathogen R. ornithinolytica, by describing its clinical and microbiological features.

\section{Case report:}

We are reporting a 29 yrs. old Saudi lady with pelvic inflammatory disease who was complaining of recurrent persistent UTI and vaginal discharge since she had an intrauterine contraceptive device (IUCD) placed. Over a year span, when she was wearing the device, she had had 5 relapses of UTI caused by different organisms including E.coli and Klebsiella. Treatment was empirical in most of the instances. Among the prescribed medications: antibiotics, antifungal and metronidazole. KUB sonography showed tiny gravels in either kidney, in addition to diffuse bladder wall thickness. Renal function was normal. Urine analyses showed hematuria and pyuria of different cell counts. At last, she opted to remove the IUCD in an attempt to stop further suffering.

Along the ten days following the removal of the device she complained of dysuria, frequency, and urgency. New urine culture recovered the rare bacterium Raoultella ornithinolytica. Based on the sensitivity result (table 1), the patient has been treated with levofloxacin antibiotic and has responded fully. 
Table 1: Microbiology report Organism: Raoultella ornithinolytica Sample source: urine

\begin{tabular}{ll}
\hline Tested antibiotics & $\begin{array}{l}\text { Raoultella Ornithinolytica } \\
\text { MIC* }\end{array}$ \\
\hline Amikacin & $\mathrm{S}$ \\
Amoxicillin/Clavulanic acid & $\mathrm{S}$ \\
Aztreonam & $\mathrm{S}$ \\
Cefepime & $\mathrm{S}$ \\
Cefoxitin & $\mathrm{S}$ \\
Ceftazidime & $\mathrm{S}$ \\
Ceftriaxone & $\mathrm{S}$ \\
cefuroxime & $\mathrm{S}$ \\
Ciprofloxacin & $\mathrm{S}$ \\
gentamicin & $\mathrm{S}$ \\
levofloxacin & $\mathrm{S}$ \\
Pipracillin/Tazobactam & $\mathrm{S}$ \\
Trimethoprim/Sulfamethoxazole & $\mathrm{S}$ \\
* MIC: Minimum Inhibitory Concentration, count $100,000 \mathrm{cfu} / \mathrm{ml}$
\end{tabular}

\section{CONCLUSION:}

R. ornithinolytica is a rare yet significant bacterium to cause typical manifestations of UTI. Infections by this bacterium should be suspected whenever the patient is wearing a urogenital device. Some of R. ornithinolytica soft tissue infections are serious enough to be life-threatening.

\section{REFERENCES:}

1. Drancourt M, Bollet C, Carta A, Rousselier P. Phylogenetic analyses of Klebsiella species delineate Klebsiella and Raoultella gen. nov., with description of Raoultella ornithinolytica comb. nov., Raoultella terrigena comb. nov. and Raoultella planticola comb. Nov. International Journal of Systematic and Evolutionary Microbiology. 2001; 51: 925-32.

2. Nakasone E, Kaneshiro R, Min K, Tokeshi J. Emergence of Raoultella ornithinolytica on O'ahu: A Case of Community-acquired R. ornithinolytica Urinary Tract Infection. Hawaii J Med Public Health. 2015 May; 74(5): 174-175.

3. Senga P, Boushab B, Romainc F, et al. Emerging role of Raoultella ornithinolytica in human infections: a series of cases and review of the literature. International journal of infectious disease. 2016; 45: 65-71.

4. Walckenaer E, Poirel L, Leflon-Guibout V, et al. Genetic and Biochemical Characterization of the chromosomal class A $\beta$-lactamases of Raoultella planticola and Raoutella ornithinolytica. Antimicrob Agents Chemother. 2004; 48(1): 305-312. 
5. Kanki M, Yoda T, Tsukamoto T, Shibata T. Klebseilla pneumoniae produces no histamine: Raoutella plantico and Raoutella ornithinolytica strains are histamine producers. Appl Environ Microbiol. 2002; 68(7): 3462-3466.

6. Hooton TM. Uncomplicated urinary tract infection. N Engl J Med. 2012; 366(11): 10281037.

AJPHR is

Peer-reviewed

monthly

Rapid publication

Submit your next manuscript at

editor@ajphr.com / editor.ajphr@gmail.com 